\title{
Microbial adherence on three different suture materials in patients undergoing periodontal flap surgery: A clinical \& microbiological study
}

\begin{abstract}
:
Sutures used during periodontal flap surgery should negate or minimize the accumulation and proliferation of microbes to the parts open to the oral cavity. Hence, microbial colonization on various intraoral suture materials from patients undergoing periodontal flap surgery and its impact on healing of gingival tissues was compared.

Patients and Methods: During periodontal flap surgery, three different suture materials (silk, polyamide, \& vicryl) were used in 25 patients. Eight days postoperatively, the sutures were removed, and adhered micro-organisms were counted by culturing on nutrient agar. Additionally clinical parameters, bleeding on probing and papillary position to assess healing were recorded to baseline, at 2 weeks, 4 weeks, and 6 weeks. Wilcoxon signed ranks test was used for statistical analysis. Results: Mean CFU's for silk, polyamide and vicryl sutures were $6.239 \pm 1.476$ X 108, $2.425 \pm 1.010 X 108,4.431 \pm 1.069 \times 108$. There was no inter-group statistical difference in the clinical parameters i.e. bleeding on probing, papillary position at all time periods $(p>0.05)$. There was a significant statistical improvement in bleeding on probing in all the three groups from base line $(p<0.05)$. Conclusions: The results of the present study demonstrated that bacteria have different affinity towards different suture materials. Monofilament polyamide suture adhered the least amount of bacteria, followed by multifilament vicryl suture, while silk adhered maximum amount of bacteria. There was no statistically significant difference in the healing of gingival tissues in between all the three groups.
\end{abstract}

Keywords: Monofilament sutures, Multifilament sutures, Colony forming units, Periodontal flap surgery

\section{Introduction-}

A suture is an artificial strand of material placed across the wound until temporary fibrin strands are formed. Sutures approximate the tissues during healing of wounds thereby promoting primary healing, and control of haemorrhage.[1]

Specific physical characteristics and properties such as good traction resistance, dimensional stability, good knot security, flexibility \& lack of memory to avoid oral mucosal damage. To avoid contamination inside the wound sutures must avoid or limit bacterial contamination to the parts which are exposed to the oral enviornment.[1] High risk patients are more susceptible to surgical site infections with severe mortality and morbidity. Precise surgical technique, appropriate antimicrobial prophylaxis, adequate skin antisepsis, and development of adjunctive strategies for minimizing microbial contamination of wound and promote wound healing. Incisional wound infections are still one of the most severe compliactions ocurring post surgically with post-

\begin{tabular}{|l|c|}
\hline \multicolumn{3}{|c|}{ Access this article online } \\
\hline \multirow{2}{*}{ Website: } & Quick Response Code \\
www.ujds.in & \\
DOI: & \\
https://doi.org/10.21276/10.21276/ujds.2020.6.2.16
\end{tabular}

opearative infections initiating in approximation of the suture lines. Scientific evidence reveals that susceptibility to infection of host tissues is increased by the prsence of suture material in the wound. It also serves as a transport media of bacteria in the surgical wounds.[2]

Speculations have existed for more than 30 years concerning the role of suture material as a seeding for infection and wound contamination, findings suggest that any biomedical device, like surgical sutures have an intrinsic affinity for accumulation of microorganisms similar to that of any other synthetic or medical device implanted internally. Microbial accumulation of sutures is a highly variable entity, various factors

\section{${ }^{1}$ SINGH P K, ${ }^{2}$ NARAYAN S J, ${ }^{3}$ NARAYAN T, ${ }^{4}$ YADALAM U, ${ }^{5}$ RAGHAVA $\mathrm{V},{ }^{6}$ SINGH I}

Address for Corresponding : Dr. Pranav Kumar Singh $643 N / 53$, Nayak Nagar, Sitapur Road Lucknow

E-mail : pranav.singh23@gmail.com

Received : 23 July 2020, Published : 31 August 2020

How to cite this article: Singh, P. K., Narayan, S. J., Narayan, T., Yadalam, U., Raghava, V., \& Singh, I. (2020). Microbial Adherence of three different suture materials in patients undergoing periodontal flap surgery. Aclinical \& microbiological study. UNIVERSITY JOURNAL OF DENTAL SCIENCES, 6(2): 28-2. 
influencong this are structure of the suture material, chemical nature of the device and is also dependent of specific microbial species. Nylon sutures tend to accumulate lesser microorganisms as compared to braided ones.[2] Throughout the lifetime oral flora undergoes changes, and inflammation in the oral cavity is highly influenced by the bacteria present. Microorgansims accumulations in small reservoirs are denoted by the topographical anatomy of the oral enviornment. Another factor to be considered for infection could be the invasiveness of the treatment in the oral microbiome. Unquestionable challenge for an operating surgeon are wound debridement and suture materials. Good vascularity of the oral cavity on one hand is supportive to early healing, whereas on the other hand presence of saliva specific bacterial microorganisms and oral functions such as speech, mastication, food swallowing require apt selection of the suture material. This plays a more significant role in individuals susceptible to endocarditits or with immunological deficiency.[3] Sutures placed in the oral microbiome act differently than those in the other parts because of the difference in the quality of tissues involved, presence of saliva, high vascularity, and functions and parafunction of oral cavity.[1] Suture materials also acts as potential risk factor for infection because of their ability to adhere pathogenic bacteria which may act as a foci for odontogenic infections. These infections are primarily caused predominantly by anaerobic bacteria and less frequently by aerobes like Peptostreptococci, Fusobacteria, Porphyromonas, Prevotella, Streptococcus sanguis, Streptococcus intermedius, and bacteroids which are usually implicated in odontogenic infections. Recent evidence suggests bacteremia due to suture removal which was described to be a positive endocarditis risk.[3] Reducing the post-operative bacterial accumulation is even more important after regenerative periodontal surgery whereby excessive bacterial accumulation caused soft tissue dehiscence and membrane exfoliation, rendering regenerative surgery a failure.[4]

Another potential application of reducing the post-operative bacterial accumulation at surgical sites is during mucogingival surgery, because more the bacterial accumulation more is the postoperative gingival recession which leads to esthetically disappointing results, so authors have recommended using only the minimal amount of sutures necessary to secure the flap as both the suture and the knot itself cause inflammation and delays wound healing.[5]
Hence the objectives of the present study are to compare and assess the oral microbial colonization on 3 different suture materials (silk, polyamide and vicryl) in patients undergoing periodontal flap surgical procedures, and to assess the impact of microbial adherence onto healing of gingival tissues.

\section{Materials \& Methods:}

25 systemically healthy patients aged around 35-55 years requiring full mouth periodontal flap surgery visiting the outpatient department of Department of Periodontics, Sri Rajiv Gandhi College of Dental Sciences \& Hospital, Bengaluru were selected. In each of these 25 patients 2 different suture materials (silk, vicryl \& Polyamide) of standard length were placed using figure of eight suturing technique following periodontal flap surgery. Data was obtained by determining the Total Colony Forming Units of bacteria on the 3 different suture materials. Sutures were removed 8 days post-operatively under sterile conditions \& according to standard procedures, immediately transferred into a sterile container containing $5 \mathrm{ml}$. of Nutrient Broth and transferred to laboratory within $1 \mathrm{hr}$. for the analysis of bacterial Colony Forming Units.

Healing was compared of the various sites where the sutures have been placed using Papillary Bleeding Index (Muhlemann H.R. 1977) \& Papillary Position - Distance between the tip of the papilla $\&$ the contact point. Both the parameters were assessed at days 0 (pre-operatively), 2 weeks, 4 weeks \& 6 weeks post-operatively. Informed consent was obtained from the patient prior to start of the procedure.

Suture materials used were Black Silk 3-0 (Ethicon), Polyamide 4-0 (Futura Surgicare) \& Vicryl 4-0 (Polyglycolic Acid)(Ethicon).

Wilcoxon signed-rank test was used for statistical analysis.

\section{Results:}

The mean bacterial colony forming units on all the three different suture materials, polyamide suture demonstrated the minimum number of bacterial colonies $(2.42 \pm 1.01$ X108), vicryl with $4.43 \pm 1.06 \mathrm{X} 108$ bacterial colonies and silk with highest number of bacterial colonies i.e. $6.23 \pm 1.47$ X108 (Table 1).

Table 2, depicts intragroup comparison in bleeding on probing at sites with all the three sutures, there was a statistically significant improvement in bleeding on probing from baseline to T1, T2 \& T3 in all the three groups. 
Table 3, depicts intragroup comparison in papillary position at sites with all the three sutures, there was a statistically significant change in papillary position from baseline to T2 \& $\mathrm{T} 3$ in all the three groups.

\begin{tabular}{|l|l|l|l|l|l|c|}
\hline & N & Range & $\begin{array}{c}\text { Mean } \pm \text { SD } \\
\left(X 10^{8)}\right.\end{array}$ & Comparison & Z & P value $^{\#}$ \\
\hline S1 (Silk) & 25 & $3.20-$ & $6.239 \pm$ & S1 vs S2 & 4.373 & $<0.001^{* *}$ \\
& & 9.34 & 1.476 & & & \\
\hline S2 & 25 & $0.47-$ & $2.425 \pm$ & S1 vs S3 & 4.374 & $<0.001^{* *}$ \\
(Polyamide) & & 4.63 & 1.010 & & & \\
\hline S3 (Vicryl) & 25 & $2.60-$ & $4.431 \pm$ & S2 vs S3 & 4.225 & $<0.001^{* *}$ \\
& & 6.90 & 1.069 & & & \\
\hline
\end{tabular}

\#Wilcoxon sign rank test; ${ }^{* *} \mathrm{p}<0.001$; Highly Significant

Table 1: Mean bacterial Colony forming units on three different suture materials

\begin{tabular}{|c|c|c|c|c|c|c|}
\hline & \multirow[t]{2}{*}{ Time } & \multirow[t]{2}{*}{$\mathrm{N}$} & \multirow[t]{2}{*}{ Range } & \multirow{2}{*}{$\begin{array}{c}\text { BOP } \\
\text { Mean } \pm \text { SD }\end{array}$} & \multicolumn{2}{|c|}{$\begin{array}{c}\text { Intra-Group } \\
\text { Comparison } \mathrm{T} 0 \text { vs } \mathrm{T} 1, \mathrm{~T} 2, \mathrm{~T} 3\end{array}$} \\
\hline & & & & & $Z$ value $\mathrm{e}^{\#}$ & P value $^{\#}$ \\
\hline \multirow[t]{4}{*}{ S1 } & T0 & 25 & $2-4$ & $2.80 \pm 0.645$ & - & - \\
\hline & $\mathrm{T} 1$ & 25 & $2-3$ & $2.56 \pm 0.507$ & 2.121 & $0.034^{*}$ \\
\hline & $\mathrm{T} 2$ & 25 & $2-2$ & $2.00 \pm 0.000$ & 3.879 & $<0.001 * *$ \\
\hline & $\mathrm{T} 3$ & 25 & $1-2$ & $1.08 \pm 0.277$ & 4.388 & $<0.001^{* *}$ \\
\hline \multirow[t]{4}{*}{ S2 } & $\mathrm{T} 0$ & 25 & $2-4$ & $2.76 \pm 0.663$ & - & - \\
\hline & T1 & 25 & $2-3$ & $2.56 \pm 0.507$ & 1.890 & $0.059^{\mathrm{NS}}$ \\
\hline & $\mathrm{T} 2$ & 25 & $2-2$ & $2.00 \pm 0.000$ & 3.755 & $<0.001 * *$ \\
\hline & $\mathrm{T} 3$ & 25 & $1-2$ & $1.08 \pm 0.277$ & 4.378 & $<0.001^{* *}$ \\
\hline \multirow[t]{4}{*}{ S3 } & T0 & 25 & $2-4$ & $2.80 \pm 0.645$ & - & - \\
\hline & $\mathrm{T} 1$ & 25 & $2-3$ & $2.56 \pm 0.507$ & 2.121 & $0.034^{*}$ \\
\hline & $\mathrm{T} 2$ & 25 & $2-2$ & $2.00 \pm 0.000$ & 3.879 & $<0.001^{* *}$ \\
\hline & $\mathrm{T} 3$ & 25 & $1-2$ & $1.08 \pm 0.277$ & 4.388 & $<0.001^{* *}$ \\
\hline
\end{tabular}

\#Wilcoxon sign rank test; NS: $p>0.05$; Not Significant; ${ }^{*} \mathrm{p}<0.05$; significant;

${ }^{* *} \mathrm{p}<0.001$; Highly significant; S1- Silk; S2- Polyamide; S3Vicryl

Table 2: Mean and Intra-group comparison for Bleeding on Probing at all time periods

\begin{tabular}{|c|c|c|c|c|c|c|}
\hline & \multirow[t]{2}{*}{ Time } & \multirow[t]{2}{*}{$\mathrm{N}$} & \multirow[t]{2}{*}{ Range } & \multirow{2}{*}{\begin{tabular}{|l|} 
PP \\
Mean \pm SD \\
\end{tabular}} & \multicolumn{2}{|c|}{$\begin{array}{l}\text { Intra-Group } \\
\text { Comparison } \mathrm{T} 0 \text { vs } \\
\mathrm{T} 1 . \mathrm{T} 2, \mathrm{~T} 3\end{array}$} \\
\hline & & & & & $\mathrm{Z}$ value ${ }^{\#}$ & $\mathrm{P}$ value ${ }^{\#}$ \\
\hline \multirow[t]{4}{*}{ S1 } & T0 & 25 & $0-2$ & $0.44 \pm 0.651$ & & \\
\hline & T1 & 25 & $0-2$ & $0.44 \pm 0.651$ & 0.00 & 1.00 \\
\hline & $\mathrm{T} 2$ & 25 & $0-2$ & $0.64 \pm 0.70$ & 2.236 & $0.025^{*}$ \\
\hline & T3 & 25 & $0-2$ & $1.08 \pm 0.572$ & 3.557 & $<0.001^{* *}$ \\
\hline \multirow[t]{4}{*}{ S2 } & T0 & 25 & $0-2$ & $0.44 \pm 0.651$ & & \\
\hline & $\mathrm{T} 1$ & 25 & $0-2$ & $0.44 \pm 0.651$ & 0.00 & 1.00 \\
\hline & $\begin{array}{ll}\mathrm{T} 2 \\
\end{array}$ & 25 & $0-2$ & $0.64 \pm 0.70$ & 2.236 & $0.025^{*}$ \\
\hline & $\mathrm{T} 3$ & 25 & $0-2$ & $1.08 \pm 0.572$ & 3.557 & $<0.001^{* *}$ \\
\hline \multirow[t]{4}{*}{ S3 } & T0 & 25 & $0-2$ & $0.44 \pm 0.651$ & 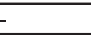 & \\
\hline & $\mathrm{T} 1$ & 25 & $0-2$ & $0.44 \pm 0.651$ & 0.00 & 1.00 \\
\hline & T2 & 25 & $0-2$ & $0.64 \pm 0.70$ & 2.236 & $0.025^{*}$ \\
\hline & $\mathrm{T} 3$ & 25 & $0-2$ & $1.08 \pm 0.572$ & 3.557 & $<0.001^{* *}$ \\
\hline
\end{tabular}

\#Wilcoxon sign rank test; NS: $\mathrm{p}>0.05$; Not Significant; $* \mathrm{p}<0.05$; significant;

$*_{* *}<0.001$; Highly significant; S1- Silk; S2- Polyamide; S3Vicryl
Table 3: Mean and Intra-group comparison for papillary position at all time periods

\section{Discussion:}

The selection for the best suture is specifically related to the procedure that has to be undertaken. Generally the suture of choice is the smallest suture that will hold the wound edges adequately.

In areas where higher tensile strength sutures are required such as nasal and oral mucosa suture of choice is synthetic multifilament suture, whereas monofilament sutures are preferred in areas demanding lower tensile strength.

Another factor to be considered during the selection of suture material is the healing speed of the tissues and patient cooperation. Non-resorbable sutures are preferred in cases where slow recovery is expected whereas resorbable sutures are used in non-collaborative patients.

Also the sutures should minimize the amount of bacterial adhesion and colonization to the parts of the sutures that are exposed to oral cavity, which in turns minimizes the wound contamination.

Sutures place in the oral cavity behave differently because the are partially embedded in the gingival and mucosal tissues with an average concentration of $7.5 \times 108$ microbes $/ \mathrm{ml}$. So these may produce prolonged tissue response as a result of microbial contamination along the suture tract.

Durdey and Bucknall6 revealed Monofilament sutures accumulate lesser quantity of microrganisms as compared to Multifilament sutures.

Multifilament suture is preferred over Monofilament suture due to its ease of manipulation, better knot property, and lack of sharp edges that cause less irritation to oral tissues.

Some studies have also challenged the use of multifilament sutures due to the wicking property, through which bacteria may seep into the oral tissues causing a prolonged and severe inflammation.[7]

After any oral or periodontal surgery, biofilms develop around the sutures giving rise to inflammation of the surrounding oral tissues; in such biofilm environment the bacteria escape the host immune responses are also resistant to antimicrobials.[3] 
The inflammation produced by these microorganisms gives rise to erythema of the tissues surrounding the suture wounds, leading the clinicians to suspect that sutures can the source that wick the bacteria in the surgical site. This swelling may in turn open up the spaces between the suture fibrils and interstitial spaces in turn enhancing the capillarity of the suture material where bacteria may invade.[7]

Although many investigators have researched to identify the properties of suture materials that lead to differential tissue reactions, until this study was undertaken, the interactions between bacteria and responsible biomaterials used in periodontal flap surgery was not considered.

The association of bacteria with silk, vicryl \& polyamide sutures were investigated in the same patient. Eight days postoperatively, sutures were removed, and adherent microorganisms were counted on nutrient agar plates.

Patients showed no signs of local infection at the time of suture removal. Also the effect of microbial; adherence to clinical healing of the gingiva was assessed through bleeding on probing and changes in papillary position at the sites where sutures were placed.

From our in vivo results, polyamide was seen to be less prone to support bacterial colonization than the two other suture materials, this is in support of other studies where silk has been showed to accumulate more number of micro-organisms than other suture materials. [8,9] This difference was also seen to be statistically significant.

Lesser accumulation of microbes on polyamide suture could be due to absence of wicking property which is seen in monofilament sutures. Whereas in a similar way silk suture accumulated more amount of microbes due to the inherent nature of wicking in the multifilament sutures.

Grigg TR and colleagues in a study conducted to demonstrate of the mechanism of wicking and to develop mechanisms and strategies to minimize the transmission of bacteria by fluid movement and bacterial colonization and expansion found that silk suture has least fluid movement by capillarity as compared to other braided suture materials, but this in-vitro study did not compare silk to vicryl or polyamide.[7]

There was no statistical difference in the clinical parameters assessed at all time periods between all the three sutures.
All the sites had similar bleeding on probing and papillary position, at all time periods.

On intra-group comparison all the three groups showed statistical improvement in bleeding on probing with time.

The results of the present study are in agreement with other authors who found no differences in serious infections when silk suture was complared with other Multi-filament sutures. 8 In the current study no effort was made to identify the bacteria present on the suture materials, and to culture the anaerobic bacteria because the sutures were placed in an aerobic environment.

Suture materials also acts as potential risk factor for infection because of their ability to adhere pathogenic bacteria which may act as a foci for odontogenic infections, this fact was not observed as a significant finding in the present study.

Otten et al 3 in his recent finding revealed that suture removal can cause bacteremia which can be implicated as a possible risk factor for bacterial induced endocarditis. Hence, suture removal at the earliest (6-10 days) is suggested post oral and periodontal surgery.

Smit et al.4 in a discussion in reaction of tissues to various suture materials used in the abdominal facial layer of rats, concluded that, at 7 th day post surgery the factor of utmost importance responsible for variation in the reaction of tissues is trauma induced during surgery, rather than the different suture materials." Hence, minimal surgical trauma, and careful and delicate tissue management should be of utmost importance to achieve uneventful and physiological wound healing.

Similar considerations will apply to oral and periodontal surgery also, but due to the saliva and huge amount of bacterial load in the oral cavity the difference in suture materials becomes more important and clinical complications and prolonged tissue responses to surgery may be a result of continuous influx of microbes along or through the suture channel.

These considerations become even more important during periodontal regenerative surgeries as the accumulation of bacteria can lead to the failure of the entire procedure alone. 4 Another situation warranting minimization of bacterial accumulation is during mucogingival surgeries whereby increased bacterial accumulation has shown to be responsible 
for increased post-operative gingival recession and in turn causing aesthetic compromise.[5]

So any procedure that minimizes the bacterial adherence during and after periodontal surgeries is of prime importance, which can be achieved just by changing the type of the suture material.

\section{Conclusion:}

Within the limits of the present study, the following conclusions can be drawn

1. Polyamide sutures accumulated the least amount of bacteria in comparison to silk and vicryl sutures.

2. There was no significant difference in the healing of gingival tissues in between all the three groups.

3. There was statistically significant improvement in bleeding on probing from baseline to T1, T2, and T3.

In this study, microbiological analysis showed minimum accumulation of bacteria on polyamide sutures than silk and vicryl sutures. It is suggested that polyamide sutures can provide better clinical outcomes during regenerative surgeries and mucogingival surgeries, where increased bacterial accumulation can have harmful clinical outcomes.

Further long term studies with larger sample size should be directed comparing the use of commonly used suture materials during periodontal surgeries.

\section{Reference:}

1. Banche G, Roana J, Mandras N, Amasio M, Gallesio C, Allizond V, et al. Microbial adherence on various intra-oral suture materials in patients undergoing dental surgery. J Oral Maxillofac Surg 2007;65:1503-1507.

2. Chu CC, Williams DF. Effects of physical configuration and chemical structure of suture materials on bacterial adhesion: A possible link to wound infection. Am J Surg 1984;147:197-204.

3. Otten JE, Wiedmann-Al-Ahmad M, Jahnke $\mathrm{H}$, et al. Bacterial colonization on different suture materials-A potential risk for intraoral dentoalveolar surgery. J Biomed Mater Res B Appl Biomater 2005;74:627-634.

4. Selvig KA, Kersten BG, Chamberlain AD, Wikesjo UM, Nilveus RE. Regenerative surgery of intra-bony periodontal defects using e-PTFE barrier membranes: Scanning electron microscopic evaluation of retrieved membranes versus clinical healing. J Periodontol 1992;63:974-978.

5. Velvart P, Peters CI. Soft tissue management in endodontic surgery. J Endod 2005;31:4-16.

6. Durdey P, Bucknall TE. Assessment of sutures for use in colonic surgery: An experimental study. J R Soc Med 1984;77:472-477.

7. Grigg TR, Liewehr FR, Patton WR, et al. Effect of the wicking behaviour of multifilament sutures. J Endod 2004;30:649-652.
8. Sugarman B, Musher D. Adherence of bacteria to suture materials. Proc Soc Exp Biol Med 1980;167:156-160.

9. Georges SR, et al. Reaction of the human gingival tissue to different suture materials used in periodontal surgery. Braz Dent J 1991;2:103-13.

10. Smit IB, Witte E, Brand R, Trimbos RJ. Tissue reaction to suture materials revisited: Is there an argument to change our views? Eur Surg Res 1991;23:347-354. 